\title{
An unusual presentation of Beckwith Wiedemann Syndrome
}

\author{
Sanath P Lamabadusuriya ${ }^{1}$, Shehan perera $^{2}$, S Abeygunasekera $^{3}$
}

Sri Lanka Journal of Child Health, 2002; 31: 128-9

(Key words: Beckwith Wiedemann syndrome)

This baby was born at term by normal vaginal delivery and weighed $4.14 \mathrm{~kg}$. Antenatal period had been uneventful with regular clinic follow up. $\mathrm{He}$ was found to have macrosomia, macroglossia, omphalocele (Figure 1) and linear fissures in ear lobules (Figure 2). He developed episodes of hypoglycaemia on the first day of life. A diagnosis of Beckwith Wiedemann syndrome was made and surgical repair of the omphalocele was done on the 2 nd day of life.

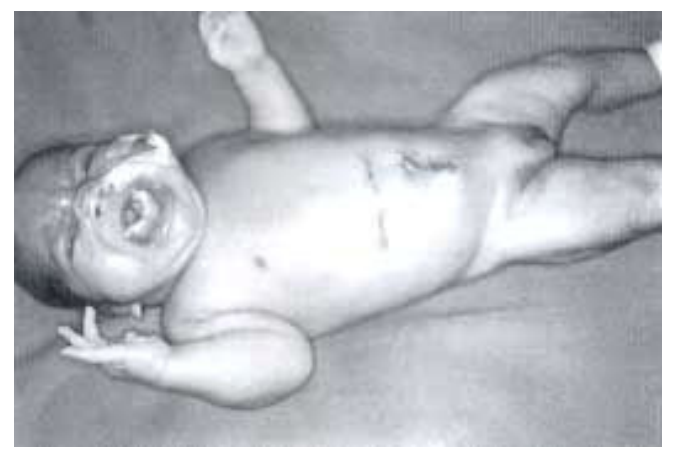

Figure 1. Macrosomia \& macroglossia

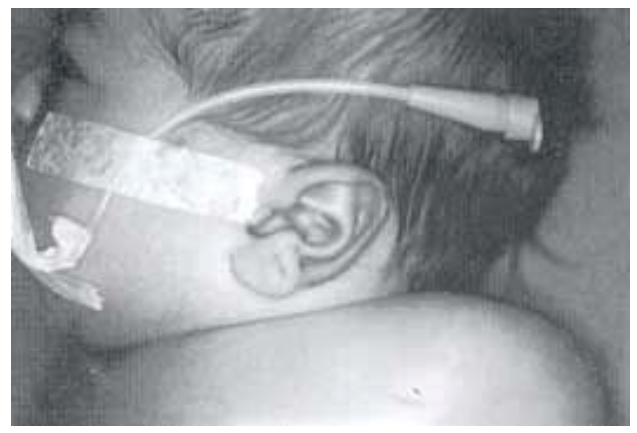

Figure 2. Linear fissures in ear lobule

Two days later he developed bilious vomiting with abdominal distension. A barium meal showed the duodenojejunal flexure displaced to the right with small intestinal bowel loops on the right side of the vertebral column (Figure 3). These findings were compatible with intestinal malrotation. An

${ }^{1}$ Senior Professor, ${ }^{2}$ Registrar, Professorial Paediatric Unit, Lady Ridgeway Hospital, Colombo, ${ }^{3}$ Surgical Registrar, Lady Ridgeway Hospital, Colombo.

(Received on 7 November 2002) exploratory laparotomy was done on the 9th day of life and the malrotation corrected. He was then transferred to a medical ward for management of persistent hypoglycaemia. He later developed pyogenic meningitis and succumbed on the 18th day of life.

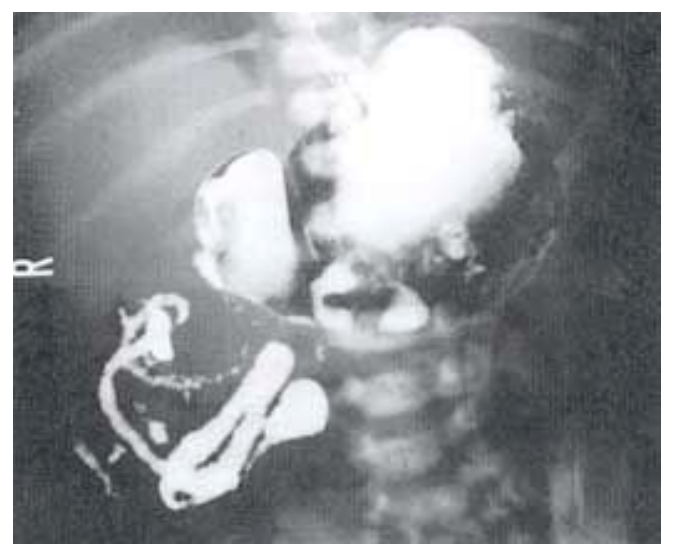

Figure 3. Barium meal showing duodenojejunal flexure and small intestinal bowel loops on right side of abdomen

Beckwith Wiedemann syndrome is usually sporadic. The gene for the syndrome is located at $11 \mathrm{p} 15.5$. The characteristic phenotype occurs as a result of a variety of different genetic mechanisms all of which result in an imbalance of the gene. Currently, it appears that maternal copy of the gene is normally imprinted or inactivated.

Therefore there is normally only one active copy of the gene functioning at any given time ${ }^{1}$. The usual abnormalities seen Beckwith Wiedemann syndrome are macrosomia (average birth weight of $4 \mathrm{kgs}$ ), macroglossia, large eyes, linear fissures in lobules of ears, large kidneys with renal medullary dysplasia, pancreatic hyperplasia, hypioglycaemia, omphalocele and other umbilical anomalies ${ }^{2}$.

Malrotation can be diagnosed by small bowel seen on the right and large bowel on the left of the abdomen. There will also be non rotation of the duodenum with duodenojejunal flexure situated in front of the vertebrae rather than to the left side of the abdomen (Figure 3). Although intestinal malrotation is common with omphalocele, a literature search done 
on Medline (1990-2001) did not reveal a single case of Beckwith Wiedemann syndrome associated with intestinal malrotation.

\section{Acknowledgements}

We thank Dr. I. N. A. Gooneratne, Consultant Radiologist, Lady Ridgeway Hospital for the radiological investigations and Ms. Hemamali Pathmathilake for secretarial assistance.

\section{References}

1. Jones K I. Smiths recognizable patterns of human malformation. 5th ed. W.B Saunders Company, 1997; 164-5.

2. Davis C F, Young D G. Congenital defects and surgical problems. In: Rennie J M, Roberton N R $\mathrm{C}$, editor, Textbook of neonatalogy. Churchill Livingstone, 1999; 775-6. 